\title{
Haemolytic anaemia associated with splenic haemangiomata
}

\author{
J.M. Radhi, J.P. Wallis and H. Mansy \\ Department of Pathology, Freeman Hospital, Newcastle upon Tyne, UK.
}

\begin{abstract}
Summary: We describe a 33 year old woman who developed unexplained haemolytic anaemia following renal transplantation and who was found to have multiple splenic haemangiomata. This case demonstrates that splenic haemangiomata may be a cause of haemolytic anaemia in the absence of abnormalities in coagulation.
\end{abstract}

\section{Introduction}

Benign tumours of the spleen are uncommon ${ }^{1}$ and include fibroma, osteoma, chondroma, lymphangioma and haemangioma. According to Husni $^{2}$ haemangiomata are the most numerous of these. The association of haematological abnormalities with certain neoplasms has received increased attention in recent years. Since the original description by Kasbach and Merrit ${ }^{3}$ many cases of thrombocytopenia associated with haemangiomata have been reported.

We report a patient with haemolytic anaemia and splenic haemangiomata who showed no evidence of coagulation abnormalities or thrombocytopenia.

\section{Case report}

A 33 year old woman presented in 1985 with haemolytic anaemia. At the age of 13 years she had been found to have vesico-ureteric reflux and severe renal scarring. Progressive renal failure led to her starting peritoneal dialysis in 1982. Following several episodes of peritonitis she was changed to haemodialysis. In 1983 she received a successful cadaver renal transplant. Azathioprine and prednisolone were used for immunosuppression and continued throughout her subsequent course. Four months after transplant her haemoglobin had risen from $6.6 \mathrm{~g} / \mathrm{dl}$ while on dialysis to $12.6 \mathrm{~g} / \mathrm{dl}$ and her serum creatinine was stable at $200 \mu \mathrm{mol} / \mathrm{l}$. Over the next six months her haemoglobin fell gradually to $8.4 \mathrm{~g} / \mathrm{dl}$ with increased reticulocytes of between 10 and $18 \%$. The previously normal peripheral blood film then showed marked tear drop poikilocytosis and polychromasia. Schistocytes were not a feature. Before haemolysis became evident platelet counts

Correspondence: J.P. Wallis B.A., M.R.C.P. Accepted: 19 August 1987 averaged $200 \times 10^{9} / 1$ and during haemolysis, $290 \times 10^{9} / 1$. White cell counts remained steady at $3-6 \times 10^{9} / 1$ during the period of study. In vivo red cell half-life measured by chromium 51 labelling of the patient's red blood cells showed a shortened halflife of 12 days (normal 25-30 days) with increased isotope uptake over the spleen but not the liver, suggesting sequestration or destruction by the spleen. Direct anti-globulin test was negative Haptoglobins were normal. All usual parameters of clotting including fibrinogen and fibrin degradation? products were repeatedly normal. Bone marrow aspirate and trephine were hypercellular with marked increase in erythropoiesis consistent with haemolysis (myeloid:erythroid ratio $=0.7: 1$ ). There was no other abnormality, in particular no increase in reticulin. Red cell osmotic fragility, red cell G6PD and pyruvate kinase, Ham's acidified serum lysis test, urinary haemosiderin, and haemoglobin electrophoresis were all normal.

An enlarged spleen was palpable $6 \mathrm{~cm}$ below the costal margin and repeated transfusions averaging two units every three weeks were required to maintain her haemoglobin.

The cause of the haemolysis was uncertain but in view of the apparent destruction of red cells by the enlarged spleen, splenectomy was performed in April 1985.

Following splenectomy her haemoglobin rose to $14.1 \mathrm{~g} / \mathrm{dl}$ and has remained at this level with normal reticulocytes. The poikilocytosis which had been prominent during the period of haemolysis was no longer a feature of the peripheral blood which shows only post-splenectomy changes. Platelets rose to $450 \times 10^{9} / 1$. Throughout the function of her renal graft remained stable with serum creatinine of 150 $200 \mu \mathrm{mol} / \mathrm{l}$.

(C) The Fellowship of Postgraduate Medicine 1988 


\section{Pathology}

The spleen was moderately enlarged and weighed $600 \mathrm{~g}$. It had a smooth outer surface and cut section revealed multiple multilocular cystic structures of variable size, the largest measuring up to $2 \mathrm{~cm}$ and situated close to the lower pole (Figure 1a). These structures were filled with dark brown fluid. Histological examination showed large and small vascular spaces lined by flat epithelium, the cells of which were shown to contain factor VIII-related antigen by an immunoperoxidase technique. These features are those of cavernous haemangiomata (Figure 1b). The rest of the spleen showed focal haemorrhage around the periphery of the haemangioma and foci of extramedullary haematopoiesis. There was no evidence of malpighian corpuscle enlargement and no evidence of red blood cell trapping in the splenic cords.

\section{Discussion}

Splenomegaly occurs in a substantial number of patients with renal failure. ${ }^{4}$ This has been attributed to both marked hypertrophy of the splenic macrophage population and chronic antigenic stimulation with subsequent increase in the splenic lymphocytes. ${ }^{5}$ In occasional patients splenomegaly is associated with hypersplenism that is severe enough to contribute significantly to the severity of the patient's anaemia. ${ }^{6}$

In this patient, a diagnosis of haemolytic anaemia was based on the peripheral blood findings, reticulocytosis, shortened red cell half life and very active erythropoiesis seen in the bone marrow, in the absence of other causes of anaemia. Her renal function was reasonable and thought unlikely to be contributing to the anaemia. The increased sequestration or destruction within the spleen were thought to be in favour of hypersplenism despite its unusual severity. Splenectomy is not without risk in immunosuppressed patients but in view of her need for repeated blood transfusion it was thought justified in this case.

No other cause of haemolysis could be found, and following removal of the tumour by splenectomy the haemolysis and associated poikilocytosis cleared completely. The increased size of the spleen was partly due to the haemangioma and partly due to extramedullary haematopoiesis, but without significant hypertrophy of normal splenic

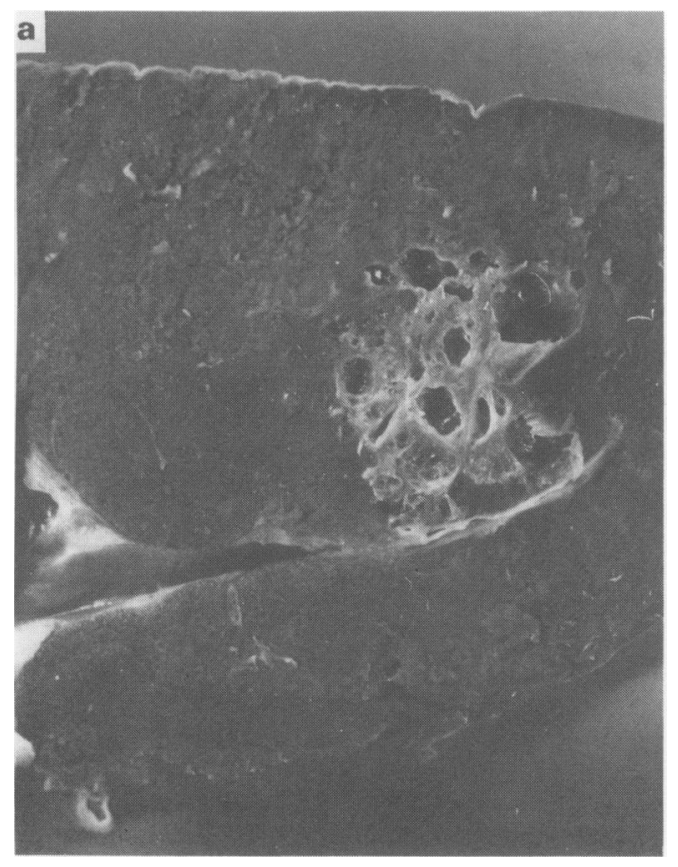

$\mathbf{m m}$

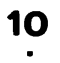

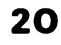

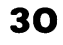

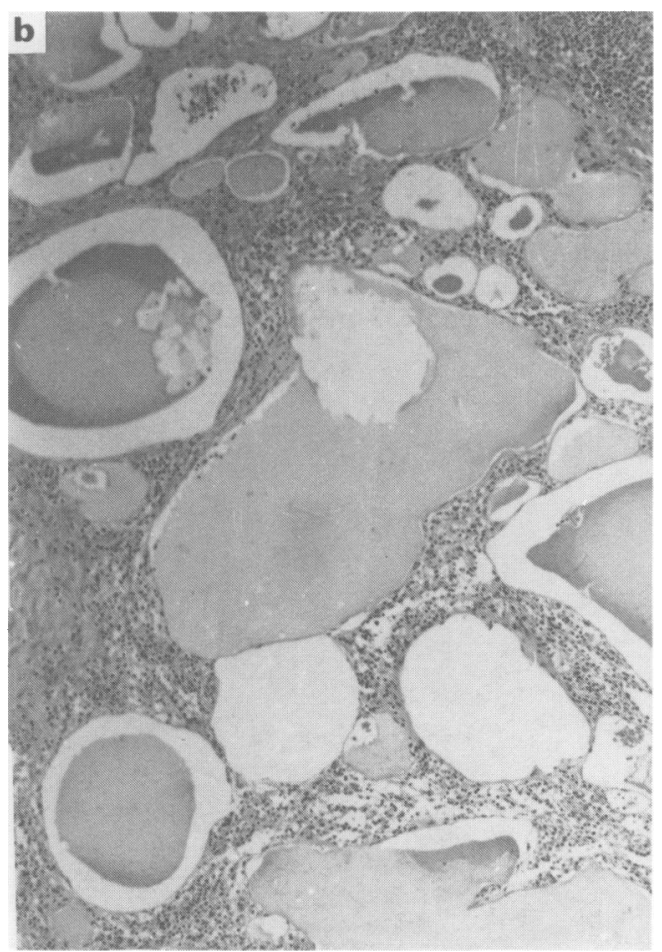

Figure 1a Multiloculated cystic structure situated near the lower pole.

Figure 1b A splenic haemangioma with varix-like vascular spaces lined by flattened endothelial cells. 
tissue. Response to splenectomy is a feature of a variety of haemolytic anaemias, and splenomegaly from other causes may give rise to a shortened red cell life span. However there seems little doubt in our case, in view of the acquired nature of the defect, the peripheral blood poikilocytosis and the pathology of the spleen, that the haemolysis was of a 'mechanical' nature and directly related to the multiple splenic haemangiomata.

In 1940 Kasabach and Merritt $^{3}$ described microangiopathic haemolytic anaemia and thrombocytopaenic purpura in a child with a haemangioma. Since then there have been many reports of similar haematological abnormalities ${ }^{7-9}$ in association with haemangiomata including those of the spleen. Cases of severe coagulation abnormalities without haemolytic anaemia have been described, but there are few if any cases described of haemolytic anaemia without an associated haemorrhagic

\section{References}

1. Pines, B. \& Rabinovitch, J. Hemangioma of the spleen. Arch Pathol 1942, 33: 487.

2. Husni, E.A. Arch Surg 1961, 83: 681.

3. Kasabach, H.H. \& Merritt, K.K. Am J Dis Child 1940, 59: 1063.

4. Hartley, L.C., Morgan, T.O., Innis, M.D. et al. Splenectomy for anaemia in patients on regular haemodialysis. Lancet 1971, ii, 1343.

5. Neiman, R.S., Bischel, M.D. \& Lukes, R.J. Hypersplenism in the uraemic in patients on regular haemodialysis. Am J Clin Pathol 1973, 60: 502.

6. Brenner \& Rector (eds.). Haematological Consequences of Renal Failure. The Kidney, Third edition. W.B. Saunders, 1986, pp. 1637-1639. diathesis. ${ }^{10}$ Our patient developed a profound haemolytic anaemia with normal platelets and no evidence at any time of abnormalities of coagulation.

It is likely that haemolysis without a disturbance of coagulation is one end of the spectrum of disorders that encompasses haemolysis with thrombocytopaenia and haemolysis with consumptive coagulopathy. Thus in the differential diagnosis of haemolytic anaemia, where poikilocytosis is a feature, splenic or other haemangiomata should be considered as a cause, despite normal coagulation and platelets.

\section{Acknowledgements}

We are grateful to Dr R. Wilkinson and Dr M.K. Bennett for permission to publish this case report. Thanks are also due to Mr P.J. Thompson for photography and Miss J.M. Lowes for the typing of the manuscript.

7. Heading, R.C., McClelland, D.B.L., Stuart, A.E. \& Hamilton, T. Ruptured angiomatous spleen presenting as a severe coagulation defect. Br J Surg 1972, 59: 492-494.

8. Albert, I.A. \& Benisch, B. Haemangioendothelioma of the liver associated with microangiopathic haemolytic anaemia. Am J Med 1970, 48: 624-629.

9. Propp, R. \& Scharfman, W. Haemangioma thrombocytopenia syndrome associated with microangiopathic haemolytic anaemia. Blood 1966, 28: 623633.

10. Dove, D.A., Laurent, G. \& Pradere, B. Presse Med 1984, 13: 740. 